\title{
Estágio em psicologia escolar e educacional e prevenção à criminalidade: ampliando perspectivas de atuação
}

\author{
Internship in school and educational psychology and crime \\ prevention: expanding work perspectives
}

Carmen Lúcia Reis (orcid.org/ 0000-0002-2370-7637)'

Anabela Almeida Costa e Santos (orcid.org/0000-0002-2376-8392) ${ }^{2}$

Luana Mundim de Lima (orcid.org/ 0000-0002-2081-252X)

Daniel Caldeira de Melo (orcid.org/0000-0002-2370-7637) ${ }^{4}$

Maria Carolina Buiatti Amaral e Silva (orcid.org/ 0000-0002-5376-7892)

Luciane Carneiro Pereira (orcid.org/0000-0002-6025-5369) ${ }^{6}$

\begin{abstract}
Resumo
Este relato apresenta uma experiência de Estágio Básico em Psicologia Escolar e Educacional desenvolvida junto ao Programa Central de Acompanhamento de Penas e Medidas Alternativas (CEAPA), do Governo de Minas Gerais. Buscou-se relatar a complexidade dessa experiência a partir de três perspectivas: docentes, profissionais da instituição e uma estagiária. O Estágio, fundamentado na parceria entre instituição e universidade, foi importante desencadeador tanto de reflexões sobre o trabalho quanto de articulações teórico-práticas, além de aproximar os estagiários de possíveis campos de atuação — sobretudo aqueles que transcendem a estrutura da escola formal — e de desafios que se apresentam no cotidiano profissional.
\end{abstract}

Palavras-chave: Estágio básico. Psicologia escolar e educacional. Atuação do psicólogo. Formação do psicólogo. Penas alternativas.

\footnotetext{
${ }^{1}$ Universidade Federal de Uberlândia, Uberlândia, Brasil. E-mail: reiscarmenpsi@gmail.com

${ }^{2}$ Universidade Federal de Uberlândia, Uberlândia, Brasil. E-mail: anabela@ufu.br.

${ }^{3}$ Universidade Federal de Uberlândia, Uberlândia, Brasil. E-mail: luana_mun_dim@hotmail.com.

${ }^{4}$ Universidade Federal de Uberlândia, Uberlândia, Brasil. E-mail: dcmelo@gmail.com..

${ }^{5}$ Universidade Federal de Uberlândia, Uberlândia, Brasil. E-mail: mariacarolinab@hotmail.com.

${ }^{6}$ Universidade Federal de Uberlândia, Uberlândia, Brasil. E-mail: lucianecarpe@yahoo.com.br.
} 


\begin{abstract}
This report presents a Basic Internship experience in School and Educational Psychology developed with the Central Program for the Monitoring of Penalties and Alternative Measures (CEAPA), of the Government of Minas Gerais. We sought to report the complexity of this experience from three perspectives: teachers, professionals at the institution and a female intern. The internship, based on the partnership between the institution and the university, was an important trigger for both reflections on work and theoretical and practical articulations, in addition to bringing trainees closer to possible fields of activity - especially those that transcend the structure of the formal school - and to challenges that present themselves in professional daily life.
\end{abstract}

Keywords: Basic internship. Educational and school psychology. Psychologist's proceedings. Psychologist's training. Alternatives to imprisonment.

Diego não conhecia o mar. O pai, Santiago Kokadloff, levou-o para que descobrisse o mar. Viajaram para o sul. Ele, o mar, estava do outro lado das dunas altas, esperando. Quando o menino e o pai enfim alcançaram aquelas alturas de areia, depois de muito caminhar, o mar estava na frente de seus olhos. E foi tanta imensidão do mar, e tanto seu fulgor, que o menino ficou mudo de beleza. E quando finalmente conseguiu falar, tremendo, gaguejando, pediu ao pai: me ajuda a olhar!

Eduardo Galeano $^{7}$

Este artigo apresentará atividades referentes ao Estágio Básico em Psicologia Escolar e Educacional, proposto por duas docentes do Instituto de Psicologia da Universidade Federal de Uberlândia (UFU) e desenvolvido junto ao Programa Central de Acompanhamento de Penas e Medidas Alternativas (CEAPA), do Governo de Minas Gerais (Minas Gerais, 2015). Visando construir um texto que abrangesse a complexidade da experiência, as professoras responsáveis, por ocasião da finalização do estágio, convidaram a equipe do CEAPA e o grupo de estagiários para escrever a respeito dessa vivência. Desse modo, o presente artigo será composto pelas produções daqueles que aceitaram o desafio de expressar por escrito os eventuais aprendizados e reflexões. Nesse sentido, apresentaremos uma breve contextualização da importância do estágio básico para a formação do psicólogo e, em seguida, relataremos o trabalho desenvolvido sob três perspectivas: das docentes,

\footnotetext{
${ }^{7}$ Galeano, E. (2011). O livro dos abraços (p. 15). Porto Alegre: L\&PM.
} 
responsáveis pela idealização e supervisão do estágio; dos psicólogos do CEAPA, que acompanharam o desenvolvimento do trabalho na instituição e; da discente, relatada por uma das estagiárias.

A epígrafe de Galeano expressa algo que tem marcado a experiência desse estágio: a necessidade demonstrada pelos estudantes de compreender quais são os possíveis campos de trabalho do psicólogo escolar e educacional e suas demandas, para poderem, futuramente, ser capazes de planejar e conduzir ações. Para isso, é preciso aprender a "olhar" por meio de uma lente que utilize os conhecimentos psicológicos aprendidos na graduação.

\section{O Estágio Supervisionado Básico: Psicologia Escolar e Educacional e a formação em} Psicologia

Refletir sobre a estruturação e condução dos estágios ganha importância no atual contexto de consolidação de mudanças substanciais na forma como se organizam os Cursos de Graduação em Psicologia. Dentre essas mudanças, destaca-se a relevância da formação para atuar no campo da educação (Peretta, Silva, Naves, Nasciutti, \& Silva, 2015).

Atualmente a formação em Psicologia é regida pelas Diretrizes Curriculares Nacionais para os Cursos de Graduação (DCN), promulgadas em 2004 (Brasil, 2004) e atualizadas em 2011, com disposições que trouxeram a necessidade de uma revisão nos cursos de graduação. Com a legislação vigente, deixa de vigorar a formação organizada e regida pelo Currículo Mínimo que, conforme descreve Yamamoto (2000), estruturava-se pelo oferecimento de todas as disciplinas teóricas nos anos iniciais do curso e dos estágios somente nos últimos períodos. Assim, passa-se da concepção de que o estágio consistia em um "campo de demonstração do ensino acadêmico" (Cury \& Neto, 2014, p. 496), para a de que é uma etapa fundamental da formação profissional, que propicia articulações teóricopráticas e compreensão do contexto profissional. Essa nova compreensão está em consonância com a Lei $n^{\circ} 11.788 / 2008$ (Brasil, 2008), que trata do estágio de formação profissional, estabelecendo que este deve preparar o futuro profissional para a vida cidadã e para o trabalho. 
Dessa forma, nas DCN, o estágio aparece como um componente da formação presente no decorrer do curso, apresentando-se logo nos anos iniciais e incluindo "o desenvolvimento de práticas integrativas das competências e habilidades previstas no núcleo comum" (Brasil, 2011, p. 7). Essa nomenclatura se refere a outra modificação substancial estabelecida pelas DCN. Em vez da tradicional formação em áreas, as Diretrizes estabelecem que o Curso de Graduação em Psicologia seja organizado em Núcleo Comum - destinado a garantir a identidade do curso de Psicologia e definido por um conjunto de competências, habilidades e conhecimentos - e ênfases. Dada a especificidade deste trabalho, cabe ressaltar que uma possibilidade de ênfase citada pelas diretrizes é nomeada "Psicologia e processos educativos", descrita como centrada no processo de educação e de ensinoaprendizagem voltado para indivíduos e grupos em distintos contextos institucionais. Consideramos fundamental que a Psicologia incorpore essa visão ampliada de educação, não circunscrita a espaços de educação formal, mas presente em instituições e grupos de ordens diversas.

\section{CEAPA: breve contextualização}

O CEAPA é um dos Programas que compõem a Política de Prevenção Social à Criminalidade instituída pelo Governo do Estado de Minas Gerais, por meio da Subsecretaria de Políticas de Prevenção Social à Criminalidade (SUPEC), ligada à Secretaria de Estado de Segurança Pública (SESP). Os Programas vinculados a tais políticas, incluindo o CEAPA, visam implantar um novo paradigma nas políticas públicas sobre segurança, que trate as questões relativas às violências e criminalidades a partir de um enfoque na cidadania e prevenção (Minas Gerais, 2015).

O CEAPA tem como objetivo acompanhar e monitorar as pessoas em cumprimento de alternativas penais substitutivas às penas privativas de liberdade, que poderiam causar suspensão de direitos políticos e cercear a liberdade. Além disso, atua sobre as vulnerabilidades sociais que coexistem com as histórias vivenciadas pelo seu público e trabalha o caráter educativo existente no cumprimento de uma pena alternativa. 
A pessoa pode chegar ao Programa CEAPA por ter recebido uma pena ou uma medida, conforme previsto pela Lei de Execução Penal (Brasil, 1984), Lei dos Juizados Especiais (Brasil, 1995), Lei das Penas Alternativas (Brasil, 1998), Código de Trânsito Brasileiro (Brasil, 1997) e Nova Lei de Drogas (Brasil, 2006). As alternativas penais acompanhadas pelo CEAPA são: prestação de serviço à comunidade (PSC) e medida educativa de comparecimento a programa ou curso educativo. Não são todos os tipos de crimes nos quais cabe uma alternativa penal. Geralmente, devem ser de baixo potencial ofensivo, com condenação de até quatro anos, o réu deve ser primário ou não reincidente em crime doloso e não ter cometido crime com violência e grave ameaça. Os tipos de delito mais comuns no CEAPA são: crimes de trânsito, porte ilegal de drogas, desacato às autoridades, furto, apropriação indébita, lesões corporais leves, estelionato (Minas Gerais, 2015).

O CEAPA é composto por uma equipe multiprofissional com formação em Direito, Psicologia e Serviço Social. O fluxo de atendimento prevê acolhimento inicial para compreensão do caso, formação de vínculo e construção das possibilidades de encaminhamento, implicando o atendido como responsável pelo cumprimento da pena ou medida aplicada. O atendido pode voltar ao CEAPA durante o processo, seja para entrega de documentos que comprovem a sua regularidade, seja para finalização da alternativa penal ou demais demandas que surjam. A equipe faz monitoramentos nas entidades parceiras para acompanhar a relação estabelecida entre instituição e atendido, prezando pela não recriminalização dos encaminhados, cuidando para que se vejam numa posição de agentes de transformação social. O resgate do caráter educativo da pena é trabalhado por meio da promoção da inclusão e emancipação das pessoas em cumprimento de alternativa penal. Esse processo, que vai além da pena, almeja superar as vulnerabilidades iniciais que os levaram ao fato delituoso e fomenta a participação, a responsabilização e a construção de relações horizontais. 
Perspectiva docente: planejando a proposta de estágio básico em psicologia escolar e educacional

O Estágio Básico em Psicologia Escolar e Educacional aqui apresentado se estruturou no cenário de mudanças na formação em Psicologia descrito anteriormente e baseou-se na construção de uma sólida parceria entre a universidade e as instituições que recebem os estagiários. Cabe destacar que a parceria com o CEAPA vem acontecendo desde 2014. Neste artigo, privilegiamos a descrição da experiência desenvolvida no primeiro semestre de 2015 .

Consideramos que a área de atuação da Psicologia Escolar não se restringe aos muros escolares e às instituições de educação formal. Como propõem Tanamachi e Meira (2003), o objeto de trabalho da Psicologia Escolar consiste no encontro entre os sujeitos e a Educação. Isso justifica a escolha do CEAPA para o desenvolvimento do estágio devido ao seu compromisso de assegurar o caráter educativo das ações que promove.

O Estágio Básico Supervisionado: Psicologia Escolar e Educacional é oferecido no $7^{\circ}$ período do Curso de Graduação com os seguintes objetivos: proporcionar reflexões sobre os saberes e fazeres em Psicologia nos contextos educativos; conhecer o funcionamento e o contexto em que se inserem diferentes instituições que trabalham com a dimensão educativa; e identificar as modalidades de atuação e as temáticas que circundam o fazer do psicólogo junto à Educação.

Para cumprir os objetivos, o grupo de estagiários realiza ao menos três visitas à instituição para desenvolvimento das seguintes atividades: conhecer a instituição; realizar observação participante do processo educativo e da atuação do psicólogo em contextos educativos; e, por fim, participar de reunião de fechamento com toda equipe. Após cada ida ao local de realização do estágio, é realizada uma supervisão com o intuito de refletir a respeito daquilo que foi vivenciado, bem como de preparar a visita seguinte. O momento de conhecer a instituição tem como propósito possibilitar que o estagiário compreenda a organização, o funcionamento, a estrutura, o organograma e as relações interpessoais da instituição. É preciso que leiam e estudem documentos que respaldem o trabalho realizado, tais como: sítio oficial das instituições, documentos de referência e legislações pertinentes à 
área. Por se tratar de um estágio básico, as atividades desenvolvidas pelos estagiários junto à instituição se basearam, sobretudo, em observações.

Adotamos a observação participante, conforme descrita por Vasconcelos (1997), a qual possibilita que os objetivos e os questionamentos do observador sejam significados a partir da convivência com os sujeitos e com o contexto investigado. Assim, o observador é ativo no processo de observação. Durante a realização dessa etapa, há uma aproximação do estagiário com o processo educativo e com a atuação do psicólogo, assim como com a equipe da instituição e com seus atendidos. Nesse momento, o discente tem a possibilidade de conhecer a dinâmica de toda a equipe envolvida no trabalho e o modo como se inserem as ações do profissional de Psicologia nesse contexto.

Todo o processo é finalizado com uma reunião de encerramento da qual participam as professoras, os estagiários e toda a equipe do CEAPA. O objetivo desse encontro é que os estagiários relatem seus aprendizados sobre o trabalho realizado e sobre o lugar que a Psicologia ocupa na instituição. Esse diálogo é mediado pela leitura de uma carta reflexiva construída pelos estagiários, sob supervisão das professoras, ao longo de todo o processo. A carta reflexiva, ferramenta citada nos estudos de Carrijo e Reis (2013), Freeman, Epston e Labovits (2001) e de Epston, White e Murray (1998), possibilita a avaliação do processo e dos resultados alcançados com o trabalho desenvolvido. As cartas são escritas a partir de questionamentos e perguntas que convidam os profissionais envolvidos a avaliar seu percurso no decorrer do trabalho. Cada estagiário elabora uma versão que é discutida coletivamente no grupo de supervisão, visando construir um documento único que será lido e discutido com toda equipe.

\section{Perspectiva dos profissionais do CEAPA: um olhar sobre as ações propostas pelo Estágio} Supervisionado Básico

Receber e acompanhar os estagiários nas atividades desenvolvidas demandaram mudanças na rotina da equipe do CEAPA. Essa suspensão do cotidiano possibilitou reflexão sobre a própria prática e sobre a responsabilidade na formação de psicólogos. Além disso, os questionamentos, as discussões e a leitura da carta proporcionaram aos profissionais do Programa diferentes formas de se relacionar no trabalho e a construção de outros olhares. 
Como observadores, os estagiários costumavam apresentar questionamentos sobre os atendimentos de maior complexidade em relação às vulnerabilidades sociais apresentadas. As maiores expectativas eram em relação à solução dos casos, às orientações fornecidas aos atendidos e à compreensão da metodologia do Programa. Esse momento era significativo para que entendessem os alcances e limites das políticas públicas nos diferentes setores de interfaces. A presença dos estagiários no CEAPA tem potencializado na equipe a discussão a respeito da atuação da Psicologia no campo da Educação em contextos para além dos muros da escola, destacadamente, no caso de uma política pública de Prevenção Social à Criminalidade, que não tem objetivos relativos à educação tão evidentes.

Uma curiosidade apresentada pelos estudantes diz respeito ao modo de contratação da equipe multiprofissional, dado que todos os profissionais são registrados como técnicos sociais, independentemente de sua formação. Foi importante esclarecer que as distintas formações dos componentes da equipe trazem vantagens como: a diversidade de conhecimentos, a partilha de experiências entre as áreas e possibilidade de crescimento profissional de todos os envolvidos.

Nos atendimentos iniciais, foi perceptível o interesse dos estagiários em entender mais sobre a forma do acolhimento, a qual foge dos moldes da Psicologia Clínica tradicional e busca escutar o indivíduo para construir com ele caminhos que o preparem para identificar, reconhecer e encontrar meios para que suas necessidades sejam atendidas. Notamos que as limitações do trabalho angustiaram os estudantes, tendo em vista que os profissionais de Psicologia não realizam atendimentos psicológicos e, em muitos casos, o trabalho, para além do cumprimento da pena ou medida alternativa, consiste em orientar a pessoa e encaminhá-la, por exemplo, para as organizações de saúde e assistência social de acordo com suas vulnerabilidades e demandas. Os estagiários puderam perceber que nos atendimentos são recebidas pessoas em situação de rua, sofrimento mental, dependência química, dentre outras demandas. São casos que precisam ser discutidos em equipe para serem realizadas intervenções antes mesmo do início do cumprimento da pena ou medida propriamente dita. A partir das reflexões dos estudantes de Psicologia expressas na carta destinada à equipe do CEAPA, ficou evidente a compreensão sobre a importância da atuação do Programa para o público atendido, como pode ser verificado no seguinte trecho: 
Acreditamos que vocês da equipe do CEAPA, juntamente às suas parcerias, possibilitam aos indivíduos criar novos sentidos, novos significados para as suas vidas e possibilidades de não reincidência, independentemente do que os levou a serem usuários do Sistema. O trabalho de vocês envolve aprendizagem, desenvolvimento, crescimento, reflexão e reconstrução, e é aí que o caráter educativo se mostrou em toda a sua intensidade. Entretanto, é necessário enxergar que nem todas as sementes germinam, assim como nem toda atividade terá um caráter educativo para todos os usuários. (Trecho da carta elaborada pelo grupo de estudantes)

A metáfora da semente utilizada no trecho acima diz de como o trabalho desenvolvido pelo Programa pode promover ao indivíduo uma reflexão sobre seus atos, sobre o acontecimento criminal e sobre seu lugar junto à comunidade. Infelizmente, nem todo solo é fértil, mas o trabalho segue sendo o de semear esse olhar, que possibilita outros sentidos para a vida, para além de uma simples não reincidência criminal.

Por fim, o retorno dado pelos estagiários quanto à experiência vivida no CEAPA promoveu algumas observações sobre a atuação dos profissionais no Programa: como não se afetar diante dos casos de violência, desigualdade e vulnerabilidades sociais apresentados nos atendidos?; como se cuidam, em termos de saúde e qualidade de vida?; como dar vazão a todos os sentimentos e pensamentos que emergem desses atendimentos?

De forma geral, para além dos cuidados particulares de cada profissional com sua própria saúde, tais reflexões fazem pensar sobre as vantagens do trabalho em equipe: a) ao proporcionar espaços para discutir os casos; b) ao dividir as impressões e as angústias que naturalmente afetam cada um e; c) ao pensar estratégias de intervenção construídas coletivamente, visando esgotar questões no próprio contexto do trabalho. É importante destacar que além do suporte interno da própria equipe, o Programa prevê um acompanhamento sistemático das equipes: a Supervisão Metodológica, que realiza intervenções pontuais quanto ao manejo dos casos, e a Gestão Social, que faz o acompanhamento cotidiano da execução do trabalho. 


\section{Perspectiva de uma estagiária}

O estágio objeto deste estudo também pode ser abordado segundo a perspectiva de uma das estagiárias. Para melhor compreender os sentidos construídos a partir dessa experiência, é importante conhecer um pouco da trajetória dessa discente nos encontros entre Psicologia e Educação.

Cursando as disciplinas destinadas à apresentação da Psicologia Escolar, embasadas na abordagem Histórico-Cultural, a estagiária aprendeu a olhar de forma ampliada para as questões educacionais, além do contexto escolar. Partindo desse pressuposto, o psicólogo escolar, segundo Meira (2003), deve ocupar "o lugar possível, seja dentro ou fora de uma instituição, desde que ele se coloque dentro da educação" (p .60). Essa afirmativa demonstra bem a variabilidade dos espaços que o psicólogo escolar pode ocupar na sociedade.

A vivência da estagiária no Estágio Básico foi algo muito almejado, devido à identificação com a proposta da Psicologia Escolar e Educacional, ao desejo de saber mais sobre práticas em tal perspectiva nos diversos contextos educativos, e à afinidade com a didática e o posicionamento teórico e prático das docentes que supervisionaram o referido componente curricular.

A experiência da discente se iniciou com a apresentação dos diferentes locais nos quais as atividades poderiam acontecer. A escolha pelo Programa CEAPA foi imediata, em face da oportunidade, até então inexistente, durante a graduação em Psicologia, de trabalhar com temáticas como a criminalidade e as políticas públicas destinadas a ela, bem como estar em contato com uma equipe multiprofissional. Além disso, houve palestras, no decorrer do próprio curso, ministradas pelo Gestor Social do Centro de Prevenção à Criminalidade ${ }^{8}$, que despertaram na estagiária o interesse pelos trabalhos sociais dos quais ele fazia parte e pelo seu modo de compreender a criminalidade. Outra motivação para escolher o CEAPA foi a curiosidade de poder visualizar o caráter educativo inserido nesse espaço, o que parecia ser um desafio. Foi pensando nisso que surgiram questões pessoais que permearam a experiência ao longo do estágio: "Será realmente possível ver a educação inserida de

\footnotetext{
${ }^{8}$ Centro ao qual se vincula o Programa CEAPA.
} 
maneira efetiva nesse contexto?", "De que modo poderei ver a educação ali?" e "De que concepção de educação eu parto?".

Com tais questionamentos e expectativas, a estagiária, os demais estagiários e as supervisoras foram às instituições. A equipe partiu de textos que levantaram discussões sobre a educação e suas questões filosóficas, sobre a observação participante da prática em escolas e de seus desafios, para depois serem lidos os textos específicos de cada instituição e, assim, conhecer-se um pouco mais sobre sua história e suas propostas.

Baseados em tal aporte, houve a primeira visita à instituição. Esse contato foi muito importante para saber um pouco mais sobre o CEAPA e sobre o contexto histórico, social e econômico no qual ele se insere. A estagiária percebeu que, no trabalho realizado pelo Programa, é necessário conhecimento das leis e das políticas públicas que o regulamentam e o norteiam; conteúdo que, a princípio, pareceu-lhe complexo e gerou algumas indagações acerca da real viabilização do que é proposto.

Além disso, o fato de o CEAPA trabalhar com uma equipe multiprofissional gerou angústia e dúvidas na estagiária, tais como: "Será que o psicólogo precisa se 'despir' do seu conhecimento de psicólogo e do seu ‘jeito' de atuar para trabalhar em tal equipe?”. Assim, seguiram-se suas preocupações quanto ao modo como o psicólogo, em comparação aos outros técnicos, atende, acolhe e encaminha os atendidos do programa para o cumprimento das medidas. A respeito disso, ela percebeu que, em uma equipe com essa configuração, os profissionais são, muitas vezes, responsáveis pelas mesmas atividades. Entretanto, cada um traz da sua formação um jeito diferente de olhar para o indivíduo e para a tarefa a ser realizada. Assim, foi possível compreender que, para atuar, o psicólogo se inspira nos aprendizados de sua formação e parte da perspectiva dos atendidos, de suas histórias, desejos, afinidades, potencialidades e limitações; a fim de selecionar atividades mais significativas para o indivíduo. A partir de conversas com a equipe, pôde-se visualizar a importância da abordagem multiprofissional para pensar os casos do dia-a-dia, de modo a abranger e compreender a complexidade dos mesmos.

Foi de substancial importância poder conhecer a instituição e poder visualizar nela a educação fluindo, como a estagiária expressou no seguinte trecho da carta preliminar: 
Vejo educação quando informam aos usuários sobre sua situação, seus direitos, seus deveres e alertam sobre os riscos que correm. Vejo educação quando, ao invés de tornarem a pena uma punição, buscam proporcionar ao indivíduo uma experiência reflexiva, fazendo-o enxergar a sua responsabilidade perante seus atos e possibilitando que ele se envolva com atividades com as quais se identifique e nas quais se empenhe para fazer o seu melhor. (L. M. Lima, carta elaborada pela estagiária, 3 de junho 2015)

Além disso, as conexões existentes entre a instituição e a Psicologia no campo da Educação ficaram muito claras para a estagiária, uma vez que a equipe multiprofissional do CEAPA e a perspectiva Histórico-Cultural que fundamenta o estágio partem de uma mesma concepção histórica para compreender o ato delituoso e a violência. Tal concepção comum compreende o indivíduo como um ser inserido em uma sociedade que possui modos de subjetivação e aposta em educação, responsabilização, potencialização e ressignificação para trabalhar com os atendidos. Assim, a Psicologia tem muito a contribuir para atender às necessidades e cuidar dos direitos básicos dessas pessoas - saúde, educação e segurança -, implicando a própria sociedade na reabilitação desses indivíduos, sem privá-los da liberdade.

Dessa forma, a estagiária afirma que algumas perguntas foram respondidas durante a experiência no estágio e outras ficaram em aberto, o que acredita ser válido e necessário. Além disso, por meio da escrita da carta para a instituição, ela pôde refletir sobre as experiências, abrir espaço para alguns questionamentos, ponderar sobre as contribuições do estágio e oferecer um retorno à equipe do Programa. Foi significativo poder conhecer o trabalho de uma equipe multiprofissional e entender mais sobre a amplitude da Psicologia Escolar e Educacional e de suas formas de atuação. Tais aspectos suscitaram o interesse por pesquisar as ações educacionais da Psicologia no campo da criminalidade, originando a temática de seu Trabalho de Conclusão de Curso (TCC), "Justiça Restaurativa: reflexões sobre intervenções alternativas com adolescentes envolvidos em conflitos", que contou com a orientação de uma das idealizadoras do estágio, a Profa. Dr.a. Anabela Almeida Costa e Santos Peretta. 


\section{Reflexões finais sobre o trabalho}

Retomando as palavras de Galeano citadas no início do texto, compreendemos a experiência do Estágio Básico em Psicologia Escolar e Educacional como um momento importante para a apreensão da articulação teórico-prática, para a aproximação do estagiário com os possíveis campos de atuação e com os desafios profissionais que se apresentam.

Estruturar o texto a partir de três olhares possibilitou entrar em contato com eventuais aprendizados e construções no diálogo entre a Psicologia Escolar e Educacional e o campo de atuação do psicólogo que transcende a estrutura da escola formal. Consideramos que o estágio básico ofertado promoveu contribuições para a formação do estudante e também para a própria instituição que, por meio das conversas e dos encontros ocorridos ao longo das atividades, criou momentos reflexivos e de tomada de consciência da dimensão educativa do trabalho realizado.

O contato com uma equipe multiprofissional mostrou-se relevante ao possibilitar que o estudante acompanhe e conheça o cotidiano, os diálogos e as reflexões vivenciadas pelo psicólogo inserido em uma equipe formada por profissionais de diferentes áreas do conhecimento. Atuar em equipes multiprofissionais é uma das habilidades preconizadas pelas DCN e foi referida por Silva e Peretta (2016) como sendo uma das menos desenvolvidas na graduação em Psicologia. Isso nos chama a atenção para a importância de que os componentes curriculares busquem ampliar a compreensão dos estudantes sobre o diálogo entre profissionais de diferentes áreas, que compreendem fenômenos a partir de pontos de referência distintos; e assegurem quais podem ser as contribuições da Psicologia nas equipes.

Também vale destacar a contribuição da experiência descrita para aprofundar o conhecimento dos estudantes sobre o funcionamento da rede e das políticas públicas, algo que ainda se apresenta como insuficiente na formação em Psicologia (Silva \& Peretta, 2016).

Outro aspecto oportunizado pelo estágio é o entendimento de que a atuação em Psicologia pode se configurar em formatos distintos do atendimento psicológico longo e continuado, muitas vezes incompatível com as dimensões concretas da vida dos atendidos e 
com o funcionamento das instituições. Isso garante o entendimento de que intervenções pontuais, quando proporcionam a adequada compreensão e atendimento das necessidades, podem ser transformadoras e emancipatórias.

O trabalho aqui descrito aponta para a necessidade de que as experiências de estágio sejam fruto de uma fortalecida parceria entre a universidade e as instituições que recebem os estagiários, contribuindo para a formulação e o desenvolvimento de políticas públicas e para o aperfeiçoamento da formação de profissionais e dos serviços oferecidos à comunidade.

\section{Referências}

Brasil, República Federativa do Brasil. (1984). Lei no 7.210, de 11 de julho de 1984. Institui a Lei de Execução Penal. Brasília, DF: Presidência da República. http://www.planalto.gov.br/ccivil_03/leis/L7210.htm

Brasil, República Federativa do Brasil. (1995). Lei $n^{\circ}$ 9.099, de 26 de setembro de 1995. Dispõe sobre os Juizados Especiais Cíveis e Criminais e dá outras providências. Brasília, DF: Presidência da República. http://www.planalto.gov.br/ccivil_03/leis/L9099.htm

Brasil, República Federativa do Brasil. (1997). Lei $n^{\circ}$ 9.503, de 23 de setembro de 1997. Institui o Código de Trânsito Brasileiro. Brasília, DF: Presidência da República. http://www.planalto.gov.br/ccivil_03/leis/L9503.htm

Brasil, República Federativa do Brasil. (1998). Lei $n^{\circ}$ 9.714, de 25 de novembro de 1998. Altera dispositivos do Decreto-Lei n ${ }^{\circ}$ 2.848, de 7 de dezembro de 1940 - Código Penal. $\begin{array}{llll}\text { Brasília, } & \text { DF: } & \text { Presidência } & \text { República. }\end{array}$ http://www.planalto.gov.br/ccivil_03/leis/L9714.htm

Brasil, República Federativa do Brasil. (2006). Lei $n^{o}$ 11.343, de 23 de agosto de 2006. Institui o Sistema Nacional de Políticas Públicas sobre Drogas - Sisnad; prescreve medidas para prevenção do uso indevido, atenção e reinserção social de usuários e dependentes de drogas; estabelece normas para repressão à produção não autorizada e 
ao tráfico ilícito de drogas; define crimes e dá outras providências. Brasília, DF: Presidência da República. http://www.planalto.gov.br/ccivil_03/_ato2004-2006/2006/lei/11 1343.htm

Brasil, República Federativa do Brasil. (2008). Lei $n^{\circ} 11.788$, de 25 de setembro de 2008. Dispõe sobre o estágio de estudantes; altera a redação do art. 428 da Consolidação das Leis do Trabalho - CLT, aprovada pelo Decreto-Lei $\mathrm{n}^{\circ} 5.452$, de $1^{\circ}$ de maio de 1943 , e a Lei $n^{\circ}$ 9.394, de 20 de dezembro de 1996; revoga as Leis $n^{\circ} 6.494$, de 7 de dezembro de 1977, e 8.859, de 23 de março de 1994, o parágrafo único do art. 82 da Lei $\mathrm{n}^{\circ}$ 9.394, de 20 de dezembro de 1996, e o art. $6^{\circ}$ da Medida Provisória $n^{\circ} 2.164-41$, de 24 de agosto de 2001; e dá outras providências. Brasília, DF: Presidência da República. http://www.planalto.gov.br/ccivil_03/_ato2007-2010/2008/lei//1 1788.htm

Brasil, República Federativa do Brasil. Ministério da Educação. Conselho Nacional de Educação. Câmara de Educação Superior. (2004). Resolução 8, de 7 de maio de 2004. Institui as Diretrizes Curriculares Nacionais para os cursos de graduação em Psicologia. Brasília, DF: CNE. http://portal.mec.gov.br/cne/arquivos/pdf/CES0804.pdf

Brasil, República Federativa do Brasil. Ministério da Educação. Conselho Nacional de Educação. Câmara de Educação Superior. (2011). Resolução $n^{\circ} 5$ de 15 de março de 2011. Institui as Diretrizes Curriculares Nacionais para os cursos de graduação em Psicologia, estabelecendo normas para o projeto pedagógico complementar para a Formação de Professores de Psicologia. Brasília, DF: MEC. http://portal.mec.gov.br/index.php?

option=com_docman\&view $=$ download\&alias $=7692-$ rces005-11-pdf\&ltemid $=30192$

Carrijo, R. S., \& Reis, C. L. (2013). Cartas Reflexivas: uma ferramenta para a Orientação

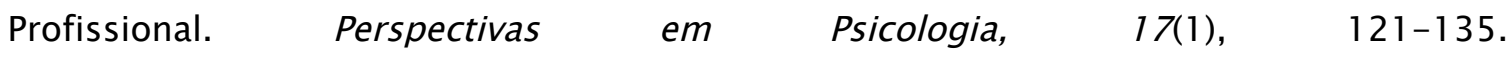
http://www.seer.ufu.br/index.php/perspectivasempsicologia/article/viewFile/ $27670 / 15150$ 
Cury, B. M., \& Neto, J. L. F. (2104) Do Currículo Mínimo às Diretrizes Curriculares: os estágios na formação do psicólogo. Psicologia em Revista, 20(3), 494-512. http://doi.org/DOI-10.5752/P.1678-9523.2014V20N3P494

Epston, D., White, M., \& Murray, K. (1998). Proposta de uma terapia de re-autoria: revisão da vida de Rose e comentário. In S. Mcnamee, \& K. Gergen (Orgs.), A terapia como construção social (pp. 117-139). Porto Alegre: Artes Médicas.

Freeman, J., Epston, D., \& Labovits, D. (2001). Elaborar um relato mediante cartas. In J. Freeman, D. Epston, \& D. Labovits, Terapia narrativa para niños: aproximacíon a los conflictos familiares através del juego (pp. 165-180). Barcelona: Paidós.

Meira, M. E. M. (2003). Construindo uma concepção crítica de Psicologia Escolar: contribuições da Pedagogia Histórico-Crítica e da Psicologia Sócio-histórica. In M. E. M. Meira, \& M. A. M. Antunes (Orgs.), Psicologia Escolar: teorias críticas (pp. 13-77). São Paulo: Casa do Psicólogo.

Minas Gerais (2015). Portfólio da Política de Prevenção Social à Criminalidade. http://www.seguranca.mg.gov.br/images/seds_docs/Prevencao/6\%20Anexo\%20V \%20Portifolio\%20CPEC.pdf

Peretta, A. A. C. S., Silva, S. M. C., Naves, F. F., Nasciutti, F. M. B., \& Silva, L. S. (2015). Novas diretrizes em tempos desafiadores: formação em Psicologia para atuar na Educação. Psicologia Escolar e Educacional, 19(3), 547-556. https://doi.org/10.1590/2175$3539 / 2015 / 0193893$

Silva, S. M. C., \& Peretta, A. A. C. (2016). A formação e a atuação do psicólogo na educação em Minas Gerais. In H. R. Campos, M. P. R. Souza, \& M. G. D. Facci (Orgs.), Psicologia e Políticas Educacionais (pp. 279-294). Natal: EDUFRN.

Tanamachi, E. R., \& Meira, M. E. M. (2003). A atuação do psicólogo como expressão do pensamento crítico em Psicologia e Educação. In M. E. M. Meira, \& M. A. M. Antunes (Orgs.), Psicologia escolar: práticas críticas (pp. 11-62). São Paulo: Casa do Psicólogo.

Vasconcelos, T. M. S. (1997). Ao Redor da Mesa Grande: a prática educativa de Ana. Porto: Porto Editora.

Yamamoto, O. H. (2000). A LDB e a psicologia. Psicologia: Ciência e Profissão, 20(4), 30-37. https://doi.org/10.1590/S1414-98932000000400004 
Reis, C. L. E† al.

Página 17 de 17

Recebido em: 4/8/2018

Aprovado em: 14/5/2020 